\title{
Silver-titanium polymeric nanocomposite non ecotoxic with bactericide activity
}

\author{
Washington Luiz Oliani ${ }^{1}$ (D) Fabio Hermes Pusceddu² \\ Duclerc Fernandes Parra ${ }^{1}$
}

Received: 17 March 2021 / Revised: 1 December 2021 / Accepted: 20 December 2021 /

Published online: 12 January 2022

(c) The Author(s), under exclusive licence to Springer-Verlag GmbH Germany, part of Springer Nature 2022

\begin{abstract}
In view of the intense interest in applications of silver nanoparticles in products for the medical field and in food preservation packaging due to their antimicrobial properties, the ecotoxicology of silver nanocomposites was evaluated in films. Test with the sea urchin Echinometra lucunter, to evaluate embryonic development and contamination by the action of silver and titanium nanoparticles in polyethylene nanocomposite films presents new results. The silver nanoparticle's stability in polymeric materials can be enhanced by adding carriers, such as titanium dioxide and montmorillonite clay (MMT) without to producing one unfriendly material. For this research, low-density polyethylene (LDPE)/linear low-density polyethylene (LLDPE) were used processed in a twin-screw extruder, followed by gamma irradiation with $25 \mathrm{kGy}$ and characterized by ecotoxicology assays, field emission scanning electron microscopy (FESEM), scanning electron microscopy and energy dispersive spectroscopy (SEM-EDX), differential scanning calorimetry (DSC), thermogravimetric analysis (TG), Raman spectroscopy (SERS) and mechanical properties. The antibacterial properties of the LDPE films were investigated against Escherichia coli and Staphylococcus aureus. The gamma irradiation had an important effect in the synthesis of silver nanoparticles resulting in bactericidal activity and the death of $100 \%$ of the tested bacteria. The evaluation of the environment was considered with the ecotoxicological investigation carried out. The results indicated that the polymeric films with silver nanoparticles and $\mathrm{TiO}_{2}$ do not contaminate the environment and neither interfere with the larval development of Echinometra lucunter. The obtained materials can be used in various applications with antimicrobial properties.
\end{abstract}

Washington Luiz Oliani

washoliani@yahoo.com.br

1 Nuclear and Energy Research Institute, IPEN-CNEN/SP, Av. Prof. Lineu Prestes, Pinheiros, São Paulo 2242, Brazil

2 Ecotoxicology Laboratory, University Santa Cecilia - UNISANTA, Oswaldo Cruz Street, 266, block B, room 02, Boqueirão, Santos, São Paulo, Brazil 


\section{Graphical Abstract}

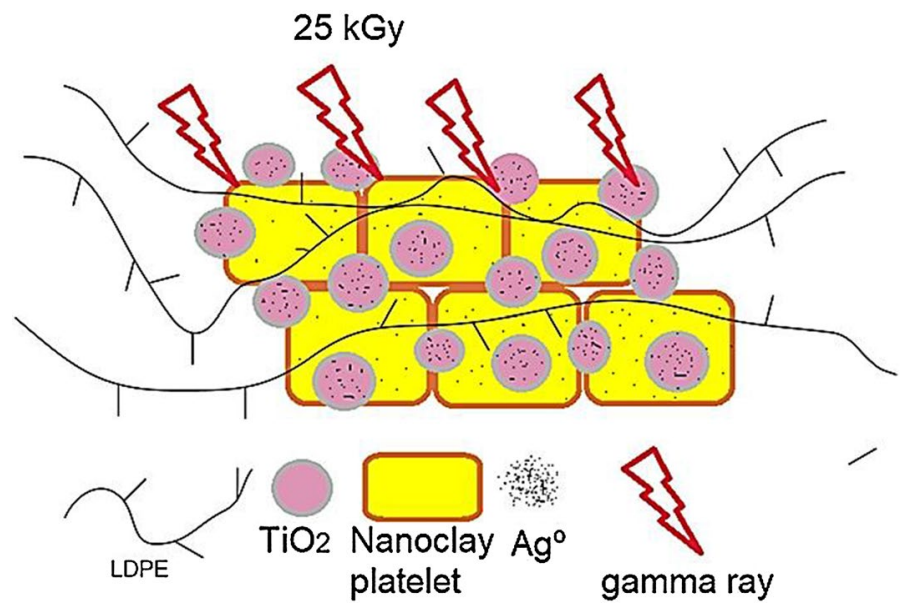

Keywords Polyethylene $\cdot$ Silver nanoparticles · Titanium dioxide $\cdot$ Antibacterial · Ecotoxicology

\section{Introduction}

The diversity of polymers and the different factors that control metallic nanoparticles' properties result in many technical applications for nanocomposites. The current nanocomposites present a relatively easy technology of preparation and application with low cost to produce new materials in substitution of available products [1, 2].

With the emergence of pathogenic bacterial strains resistant to one or more antibiotics, the medicine needs new disinfection systems. Metallic nanoparticle systems are one of the most promising systems for fulfilling this function [3-6].

Antimicrobial materials are not only used in medical applications, such as catheters [7] and prostheses [8], but also in food packaging [9, 10] and in paint industry [11] among others. One must be aware of the different public sectors where there is the possibility of proliferation of bacteria and fungi, such as hospitals, schools, offices, etc., where infectious diseases can be transmitted through surfaces [12]. In our days, plastics more than ever constitute these surfaces. Among the polyolefins, LDPE has important properties: low (weight, temperature toughness, density, moisture absorption), great mechanical properties, good processability, high stiffness in molded parts, tear-resistance besides being recyclable [13-18]. For these properties, LDPE has a wide field of applications in which the biocidal activity can be added based on many examples of polymers cited in the literature. For example, the Polyvinyl butyral (PVB) with different types of nanoparticles showed antibacterial properties. It gained mechanical resistance compared to conventional polymers [19]. 
Polyacrylonitrile nanocomposite (PAN) films containing silver nanoparticles developed as multifunctional film matrix with has biocidal activity [20]. In parallel, direct surfaces treatment of as for PP (amphiphilic polymer) of PP-g-PEG sheets having embedded metal nanoparticles were synthesized with antibacterial efficiency [6]. Investigation of it on biomaterials, as the literature reports, showed the efficacy in preventing infection of a newly developed PP-g-PEG and Ag-PPg-PEG polymer-coated shunt catheters. Especially Ag-PP-g-PEG polymer coating was effective to prevent implant-related infections in the central nervous system in rats [21].

Another example is the study of PET-g-MAA fibers coated with AgNPs that had an antimicrobial effect on both bacterial species (E. coli and S. aureus). The synthesized material was obtained easily and cheaply with surface-bound $\mathrm{Ag}+$ ions converted to AgNPs (silver nanoparticles) without using any chemical reducing agents and had no cytotoxicity effects on L929 fibroblast cells [22].

Silver nanoparticles coated with poly(styrene-g-soybean oil) graft copolymers using soy oil macroperoxide as a nanosilver carrier. The polyolefin became an efficient bactericide, in addition to producing nanocomposites with fluorescence properties, making them promising materials [11]. PET fabrics knew for not preventing the growth of microorganisms, when PET surfaces were firstly modified by MAA grafting and HMDA attaching, and after modified by silk Sirina-AgNPs immobilization. It was found that the PET S-AgNPs had antimicrobial activity on both gramnegative and gram-positive bacteria [23]. The number of applications for AgNPs increases exponentially, including nanosilver in association with other metallic nanoparticles [24]. With this, the search for new antimicrobial and antiviral materials becomes timely and eminet, including in the fight against Covid 19 [25, 26].

Silver and titanium nanoparticles are known for their biomedical properties in common uses [27]. $\mathrm{TiO}_{2}$ is an antimicrobial agent effective in bacterial cells, fungi, algae, and viruses. Its photodegradation is due to the high oxidizing action and hydroxyl radicals $\left(\mathrm{OH}^{*}\right)$ species in oxidation systems. The photocatalytic property of $\mathrm{TiO}_{2}$ is manifested under ultraviolet light. The doping of $\mathrm{Ag}$ nanoparticles in $\mathrm{TiO}_{2}$ not only increases the photocatalytic activity of titania, but also promotes properties of antibacterial activity for the material in the absence of ultraviolet light [28].

The improved photocatalytic activity of $\mathrm{Ag} / \mathrm{TiO}_{2}$ thin film for disinfection can be attributed to the higher production rate of ROS reactive species, compared to $\mathrm{TiO}_{2}$ [29].

The addition of clay-like montmorillonite strengthens the polymeric compound favoring the nucleation of silver nanoparticles. The parallel stacked layered clay structure facilitates the controlled diffusion of silver nanoparticles [30]. The creation of a biocidal material with slow release of silver species can prolong the biocidal activity [31, 32].

At the cellular level, many mechanisms of AgNPs toxicity were reported. This includes the generation of reactive oxidative species (ROS), DNA damage, and cytokine induction during in vitro studies [33]. On the surfaces, the dissolution of AgNPs releases silver ions that trigger the inactivation of respiratory enzymes, interrupt electron transport, and alter the permeability of the bacterial membrane and viral protein wrap, which causes the death of cells [29]. 
In contrast to the benefits, it can increase the disposal of nanoparticles into the environment. Consequently, it is necessary to be very careful with the application of nanomaterials, as the beneficial properties derived from them can be lost due to inadequate use in biological systems [27] in which cytotoxicity testing [34] and ecotoxicity testing [35] are of great importance.

In this context, the literature also describes the interest in ecotoxicology tests for the evaluation of nanocomposites. The sea urchin Echinometra lucunter, which populates all the Brazilian coast, is used in ecotoxicology tests due to the sensitivity of the early embryonary stages for numerous laboratories of marine coast. For pollutants present in seawater, even in very low concentrations, bioassays routinely use sea urchin larvae embryos to assess water quality [36-38].

For these senses, in present work on LDPE nanocomposites proposed the investigation of ecotoxicity of the material in urchin larvae. The innovative aspect of our study is to improve antimicrobial properties to the surface of LDPE nanocomposites by gamma irradiation, as an effective process for totally reducing metallic ions simultaneously to sterilization without chemicals. Evaluation of nanocomposites activity evolving the irradiation for efficient silver nanoparticles on $\mathrm{TiO}_{2}$ carrier reduced the formation of agglomerates, consequently, improved bactericidal efficiency.

\section{Material and methods}

\section{Materials}

LDPE with a melt flow index-MFI $\left(190{ }^{\circ} \mathrm{C}, 2.16 \mathrm{~kg}\right)$ of $0.27 \mathrm{~g} / 10 \mathrm{~min}$ and density of $0.92 \mathrm{gcm}^{-3}$ from Braskem, LLDPE with MFI $\left(190{ }^{\circ} \mathrm{C}, 2.16 \mathrm{~kg}\right)$ of $0.80 \mathrm{~g} / 10 \mathrm{~min}$ and density $0.92 \mathrm{gcm}^{-3}$ in the form of pellets provided by Braskem. The silver nitrate $\left(\mathrm{AgNO}_{3}\right)$ and Polyvinylpyrrolidone (PVP) K30 powder, average molecular weight $=51,000 \mathrm{gmol}^{-1}$ were supplied by Synth. Titanium (IV) isopropoxide, $\left(\mathrm{C}_{12} \mathrm{H}_{28} \mathrm{O}_{4} \mathrm{Ti}\right) 97 \%$, formula weight $=284.22 \mathrm{gmol}^{-1}$ and density $0.96 \mathrm{gcm}^{-3}$ was supplied by Sigma-Aldrich. Antioxidant Irganox ${ }^{\circledR}$ B215 ED from BASF and the clay Cloisite-20A were provided by BYK Additives.

\section{Synthesis of nanoparticles}

Synthesis of silver nanoparticles and titanium: PVP solution was prepared in deionized water heated at $60{ }^{\circ} \mathrm{C}$, followed by $\mathrm{AgNO}_{3}$ solubilization with constant agitation. Subsequently, the solution was followed by addition of titanium (IV) isopropoxide and MMT clay. Sonication was carried out for $30 \mathrm{~min}$ to reduce and stabilize the silver under titanium nanoparticles. The equipment used for disruption of agglomerates of silver and titanium nanoparticles in PVP solution was the EcoSonics ultrasound, with a working frequency of $60 \mathrm{kHz}$ and output with a maximum intensity of 350 Watts. 


\section{Preparation of nanocomposites films}

The polyethylene composites (LDPE/LLDPE 90:10 wt\%) were processed in a twin-screw extruder (Haake, Model Rheomex PTW 16/25), with the following processing conditions: the temperature profile (feed to die) was 160 to $190{ }^{\circ} \mathrm{C}$, with a speed of $100 \mathrm{rpm}$. From five different nanocomposites of polyethylene LDPE/LLDPE films, PENC1 to PENC3 were obtained under those conditions containing nanosilver-titanium/MMT in different ratios. The films, PENC4 and PENC5 were, finally, irradiated under air at room temperature, in a ${ }^{60} \mathrm{Co}$ gamma source, at a dose rate of $5 \mathrm{kGy} \mathrm{h}^{-1}$. The total dose absorbed was $25 \mathrm{kGy}$ (monitored by a Harwell Red Perspex 4034 dosimeter), Fig. 1.

According to the literature, the polyethylene montmorillonite nanocomposites prepared with the addition of powder from sonication process showed improvement of the dispersion compared with non-treated ones [39]. The use of ultrasound is one important tool in nanoparticles research as reported by [38] that confirmed increasing of the surface content of $\mathrm{Ag}$ on $\mathrm{TiO}_{2}$ [40].

The formulation of polyethylene nanocomposite (PENC) is shown in Table 1.

Simplified Scheme 1 of the preparation process of polyethylene nanocomposite represents the polymer matrix of the polyethylene being irradiated with gamma rays. The distribution of the clay is preferably exfoliated and the AgNPs@ $\mathrm{TiO}_{2}$ are anchored in LDPE/LLDPE matrix.

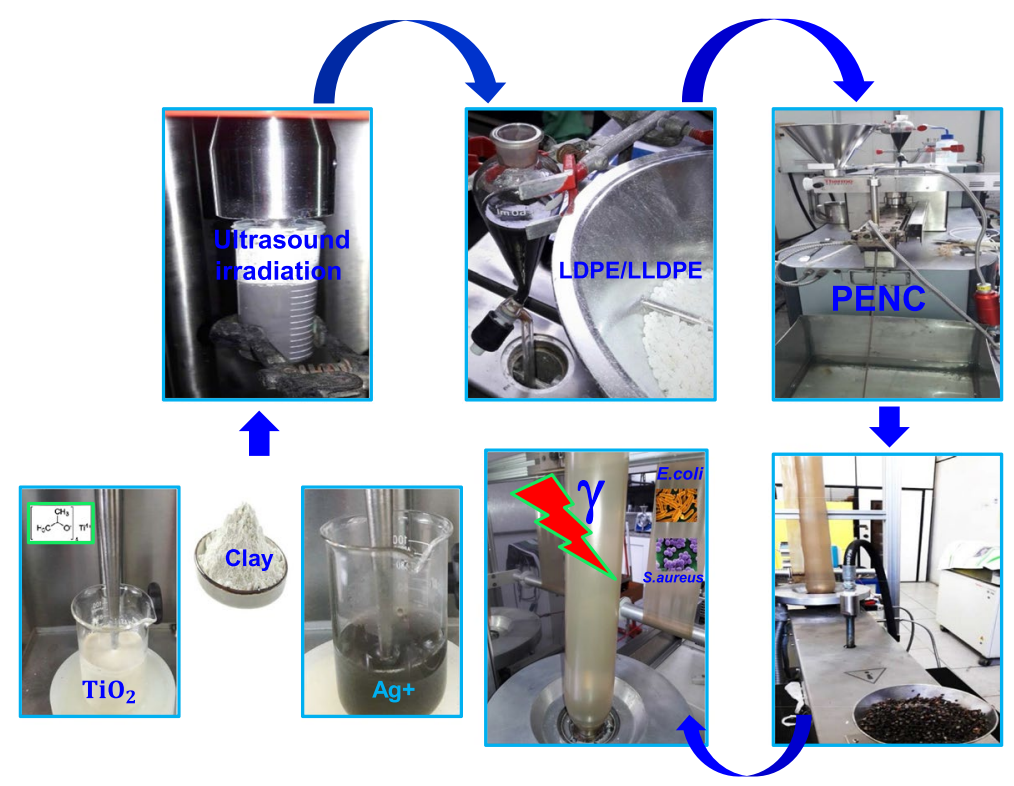

Fig.1 Experimental procedure from synthesis to gamma source irradiation process of nanocomposites 
Table 1 Formulation of nanocomposites PENC (wt\%)

\begin{tabular}{lllllc}
\hline Sample & \%Irganox & Dose/kGy & $\% \mathrm{TiO}_{2}$ & $\% \mathrm{AgNO}_{3}$ & $\% \mathrm{MMT}$ \\
\hline PE0 Pristine & 1 & - & - & - & - \\
PENC1 & 1 & - & 0.1 & 0.5 & - \\
PENC2 & 1 & - & 0.1 & 0.5 & 1.0 \\
PENC3 & 1 & - & 0.1 & 1.0 & 1.0 \\
PENC4 & 1 & 25 & 0.1 & 0.5 & - \\
PENC5 & 1 & 25 & 0.1 & 1.0 & 1.0 \\
\hline
\end{tabular}

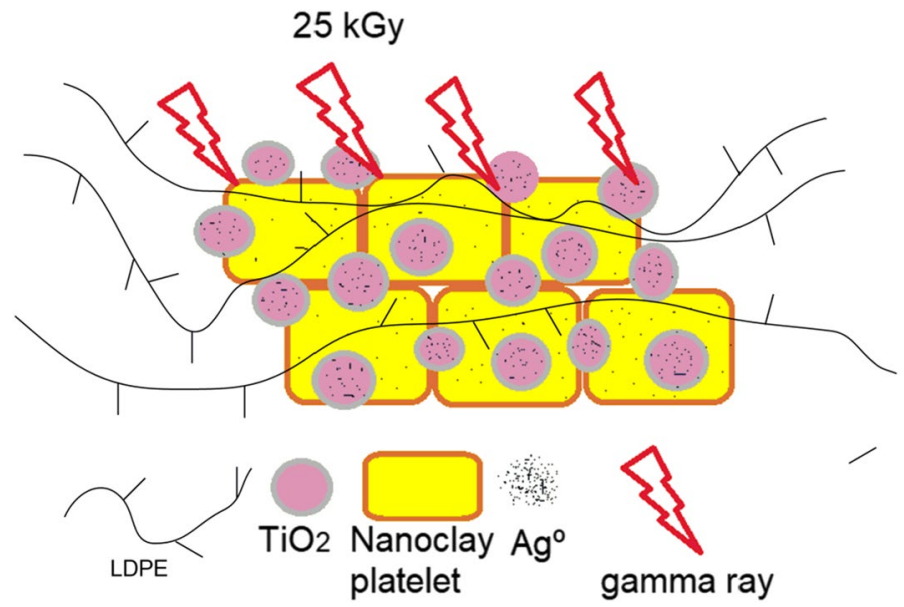

Scheme 1 Model illustrates stabilization and distribution of AgNPs@ $\mathrm{TiO}_{2}$ and nanoclay-platelet in film of polyethylene nanocomposite (PENC)

\section{Characterization of nanocomposites}

\section{Ecotoxicity}

Specimens of Echinometra lucunter were collected at Santos Bay, SP/Brazil. After the collection, the sea urchins were transported in cool boxes to the UNISANTAEcotoxicology Laboratory and placed in $500 \mathrm{~L}$ tanks with aerated seawater before testing. The gametes were obtained by $\mathrm{KCl}(0.5 \mathrm{M})$ injection according to standard [41]. As soon as the organisms started releasing the gametes, they were targeted for the fertilization procedure. These experiments are internationally accepted as suitable for toxicity, hazard, or risk assessments [36, 37, 41], and have been employed to better understand negative effects on reproduction of an organism broadly recommended for water bioassays.

The short-term chronic toxicity tests with Echinometra lucunter were carried out according to the procedure described by USEPA with adaptations [41], sea urchin embryos are exposed to a specimen of the 
PENC $=$ Polyethylene-Nanocomposite-Films samples. After the exposure period, the number of larvae that showed normal and anomalous development is evaluated.

The dilution water used in the experiments, both for obtaining gametes and for preparing controls and elutriate samples, was prepared by diluting sea salt (Redsea $\left.{ }^{\circledR}\right)$ in distilled water, in concentrations of 30 to $36 \mathrm{ppm}$, followed by filtration in cellulose membrane with $0.22 \mu \mathrm{m}$ porosity. The experiments were conducted in test tubes containing $10 \mathrm{~mL}$ of the test solution.

For each treatment, four replicates were used, where about 300 eggs were inserted, and the set was kept for 36 to $42 \mathrm{~h}$ (until observes the Initial formation of the embryos) in an incubator chamber with a constant temperature of $(26 \pm 1)^{\circ} \mathrm{C}$ and a photoperiod of $16 \mathrm{~h} / 8 \mathrm{~h}$ (light-dark). After the exposure period, the test was ended by adding of $0.5 \mathrm{~mL}$ of borax-buffered formaldehyde to all replicates.

Subsequently, the content of each replica was observed using a Sedgewick-Rafter microscope. The first 100 embryos were counted and their degree of development was assessed. Embryos that reached a well-developed pluteus larva stage were considered normal, while those that presented morphological changes and/or developmental delay were considered affected. The test was considered valid when $\geq 80 \%$ of larvae are successfully developed in the control.

\section{Statistical treatment}

The results of the chronic toxicity tests were submitted to the variance analysis method (ANOVA). First, the data were analyzed for normality and homogeneity of variance by the Chi-square and Bartlett's methods, respectively. Subsequently, the data were submitted to the analysis of variance method (ANOVA $-p<0.05$ ) using the Dunnett method.

\section{Antibacterial activity}

The cell suspension concentration of the inoculum used for tests was $\left(2.4 \times 10^{5}\right.$ $\mathrm{CFUmL}^{-1}$ ) for Staphylococcus aureus (ATCC 6538P) and $\left(2.7 \times 10^{5} \mathrm{CFUmL}^{-1}\right)$ for Escherichia coli (ATCC 8739) for each tested step. The procedure was performed separately for each microorganism. Control and test surfaces are inoculated with microorganisms, in triplicate, and then the microbial inoculum is covered with a thin, sterile film. Covering the inoculum spreads it, prevents it from evaporating, and ensures close contact with the antimicrobial surface. The samples of the PENCs films, $(40 \times 40) \mathrm{mm}^{2}$, were deposited in a sterile Petri dish inoculated on the surface of $50 \mathrm{~mL}$ of a suspension of each organism. All samples were incubated for $24 \mathrm{~h}$ at $37^{\circ} \mathrm{C}[42]$.

\section{FESEM-EDX}

The specimens were fixed in a sample holder and covered with $\mathrm{Au} / \mathrm{Pd}$ for test. The acceleration rating used was $10 \mathrm{kV}$ and the equipment was FESEM, JEOL, JSM-6701F-Japan. 


\section{SEM-EDX}

The samples were fixed in a sample holder and covered with $\mathrm{Au} / \mathrm{Pd}$ and analyzed using a Hitachi TM3000, coupled with a Bruker Quantax 70 for the collection of energy-dispersive X-ray spectroscopic information. The EDS analysis was carried out at $15 \mathrm{kV}$ and the acquisition period was $90 \mathrm{~s}$.

\section{DSC}

The thermal properties of the nanocomposite films were verified in the Mettler Toledo DSC $822^{\mathrm{e}}$ equipment. Samples weighing 10 to $15 \mathrm{mg}$ were placed into an aluminum pan. The samples were heated from $-20{ }^{\circ} \mathrm{C}$ to $220{ }^{\circ} \mathrm{C}$ and kept at 220 ${ }^{\circ} \mathrm{C}$ for $5 \mathrm{~min}$. After this isothermal process, the samples were cooled to $-20^{\circ} \mathrm{C}$ and then heated to $220^{\circ} \mathrm{C}$. The heating rate consists of $10^{\circ} \mathrm{C} \mathrm{min}{ }^{-1}$ in a nitrogen atmosphere. The melting temperature $\left(\mathrm{T}_{\mathrm{m}}\right)$ and degree of crystallinity $\left(\mathrm{X}_{\mathrm{c}}\right)$ were calculated with the following Eq. (1):

$$
X c=P \times \frac{\triangle H f}{\triangle H 0} \times 100
$$

The value of $\Delta \mathrm{H}_{f}$ is melting enthalpy of the sample, $\Delta \mathrm{H}_{0}$ was taken for $100 \%$ crystalline LDPE, which is assumed to be $280 \mathrm{kJkg}^{-1}[43,44]$, and $\mathrm{P}$ was the fraction content of LDPE in the sample.

\section{TG}

TG curves were acquired in the equipment TGA/SDTA 851-Mettler-Toledo. Samples of 10 to $15 \mathrm{mg}$ were placed into an alumina pan, under a nitrogen atmosphere of $50 \mathrm{mLmin}^{-1}$, and heated from 25 up to $600{ }^{\circ} \mathrm{C}$, at heating rate of $10^{\circ} \mathrm{Cmin}^{-1}$.

\section{SERS}

Raman analysis was performed using the Raman laser $785 \mathrm{~nm}$, InPhotonics equipment.

\section{Mechanical properties}

The mechanical properties of tensile stress and elongation at rupture followed ASTM-D882-18 [45]. The tests were performed on an Instron 5567 machine at a rate of $50 \mathrm{~mm} \mathrm{~min}^{-1}$ speed and equipped with pneumatic claws. Dimensions of the test specimens were $(70 \times 10) \mathrm{mm}$ and $0.08 \mu \mathrm{m}$ thick. Five specimens were tested for the mechanical properties of each composite formulation. 


\section{Results and discussion}

\section{Ecotoxicity}

Research on the toxicity of NPs can be investigated from two points of view: health and environmental hazard [46]. Morphological properties of the AgNPs influence their biocidal activity, for example: size, shape, and surface coating. It is important to note that same property also influences the cito and ecotoxicity of the AgNPs. These properties of AgNPs, combined with their high production volume, are a stimulus for research on the impact and harmfulness of silver nanoparticles [47, 48].

There is concern about increasing the use of manufactured nanomaterials, for example, $\mathrm{TiO}_{2}$ and AgNPs, and their possible release into the environment via wastewater treatment plants. It poses a potential threat for aquatic organisms, and its effect on the ecosystem is of great importance for environmental risk assessment. Figure 2 shows the larval development of Echinometra lucunter exposed to different polyethylene nanocomposite films.

Results of the embryo larval bioassay using E. lucunter are shown in Fig. 2. In all nanocomposite polyethylene films containing silver and titanium nanoparticles, satisfactory larval development was observed in the ecotoxicity tests, above the control value sample (PE0). With those results, it was verified that the normal development of E. lucunter larvae was not affected by silver and titanium nanoparticles of the PENC nanocomposite films.

\section{Antibacterial activity}

The interesting result illustrated in Fig. 3 is that all nanocomposite films were effective in reducing $E$. coli and $S$. aureus.

The nanocomposite polyethylene films showed significant results against the bacteria $S$. aureus and E. coli. The percentage of surviving microorganisms decreased

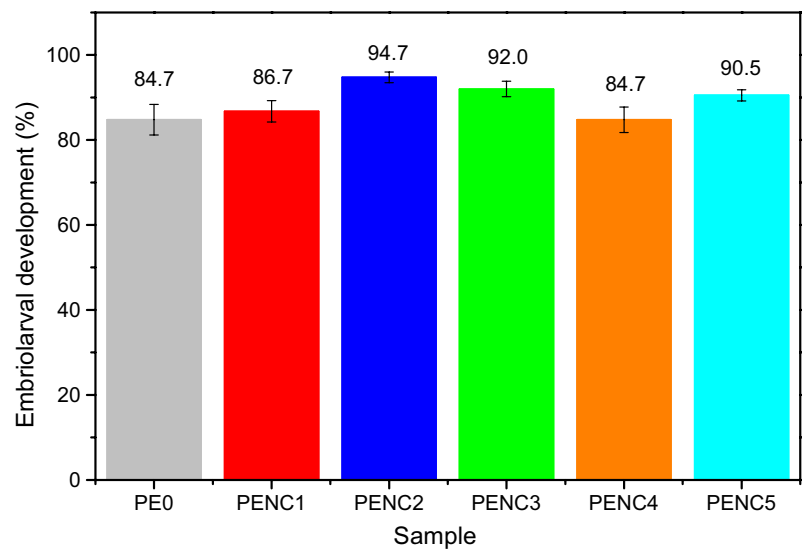

Fig. 2 Results (mean and standard deviation) of Echinometra lucunter embriolarval development for different PENC films; PE0 = control 


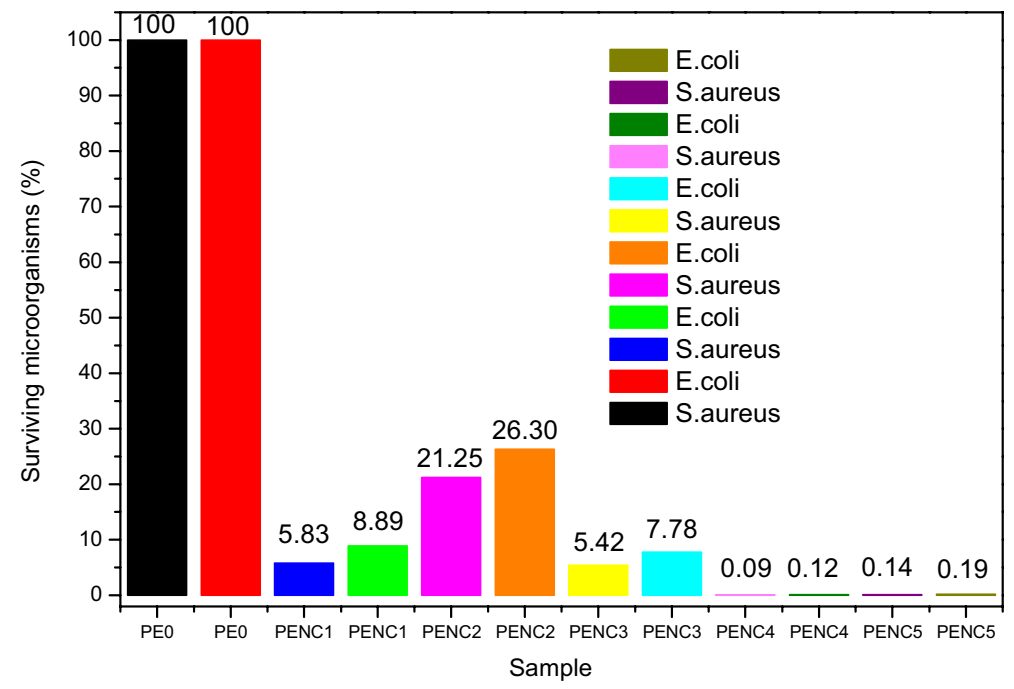

Fig. 3 Antimicrobial activity of PENC films. Obs.: PE0=Control

Table 2 Antibacterial reduction rate, R(\%) value, of polyethylene nanocomposite

\begin{tabular}{lllll}
\hline & S.aureus & S.aureus & E.coli & E.coli \\
\hline Sample & *Reduction (\%) & $\begin{array}{c}\text { Logarithmic } \\
\text { reduction-R }\end{array}$ & *Reduction (\%) & $\begin{array}{c}\text { Logarithmic } \\
\text { reduction-R }\end{array}$ \\
PE Pristine & 0 & 0 & 0 & 0 \\
PENC1 & 94.17 & 0.23 & 91.11 & 1.05 \\
PENC2 & 78.75 & 0.67 & 73.70 & 0.58 \\
PENC3 & 94.58 & 1.27 & 92.22 & 1.11 \\
PENC4 & 99.91 & 3.04 & 99.88 & 2.94 \\
PENC5 & 99.86 & 2.85 & 99.81 & 2.71 \\
\hline
\end{tabular}

significantly in the PENC1 sample with $5.83 \%$ for S. aureus and $8.89 \%$ for E. coli, whereas for the PENC2 sample is increased to $21.25 \%$ for $S$. aureus and $26.30 \%$ for E. coli, also indicative of a good result. For the PENC3 film, the results were more expressive $(S$. aureus $=5.42 \%$ and $E$. coli $=7.78 \%$ ) suggests that increasing silver to $1 \mathrm{wt} \%$ has one significant effect on activity against microorganisms.

The PENC4 and 5 films originated, respectively, from PENC1 and PENC3 irradiated at a dose of $25 \mathrm{kGy}$. The results showed a remarkable efficiency of irradiation in the reduction of ions to nanosilver with consequence of total bacteria death, reaching values very close to zero.

Table 2 reports the antibacterial reduction rate of samples composed of PENC films, using samples in dimensions of $(40 \times 40) \mathrm{mm}^{2}$, according to standard test JIS Z 2801 [42]. 
Regarding PENC3 compounds with $1 \mathrm{wt} \%$ of silver particles and titanium, is remarkable a significant antimicrobial activity against $S$. aureus with antimicrobial activity values of 1.27 and 1.11 for $E$. coli, respectively (see Table 2). In addition, the results of the sample irradiated with $25 \mathrm{kGy}$, PENC4, showed a very significant antimicrobial activity for $S$. aureus, 3.04, and E. coli, 2.94, and also for the PENC5 sample $S$. aureus 2.85 and $E$. coli 2.71 .

The results of logarithmic reduction, are very expressive for the irradiated samples PENC4 and PENC5 that presented values 2.85 for S. aureus and 2.71 for E. coli.

The high visible light photocatalytic activity of the $\mathrm{Ag} / \mathrm{TiO}_{2} / \mathrm{MMT}$ is ascribed owing to the increase in surface-active centers and the localized surface plasmon effect of the silver nanoparticles. Under visible light irradiation, the electrons generated on the silver nanoparticles from the plasmon excitation are transferred to the neighboring $\mathrm{TiO}_{2}$ particles, which function as the photocatalytic centers [49].

The release of $\mathrm{Ag}^{+}$present in the polymer surface depends on the diffusion of water molecules coming from the bacteria medium into the surface of particles [50]. Highly non-polar polymers such as allows the diffusion of those water molecules on interface through holes or micron-scale defects [51]. Gamma irradiation induces ionization and excitation of the water molecules, generating radiolytic molecular and radical species such as solvated electrons, hydroxyl radicals, and hydrogen atoms. The solvated electrons and hydrogen atoms reduce the metal ions to metal atoms, which coalesce to form more nanoparticles [52].

Polymeric nanocomposites irradiated with gamma radiation acquire more comprehensive biocidal properties compared to non-irradiated ones. The nanocomposite is effective against tested pathogenic microorganisms due to its high surface area and reduction in aggregates size due to the gamma rays [53] in surface of the carrier $\mathrm{TiO}_{2} / \mathrm{MMT}$ to perform a more stable bactericide activity.

\section{FESEM-EDX analysis}

It was possible to identify the presence of silver and titanium nanoparticles by EDX analysis. The distribution of silver and titanium in the films surfaces was homogeneous. The micrograph showed in Fig. 4, in nanometric scale indicates the presence of silver and titanium nanoparticles in spherical format and with dimensions from 53.2 to $91.1 \mathrm{~nm}$.

Figure 4 shows the FESEM micrographs of the nanocomposite film PENC1.

The deposition of AgNPs on $\mathrm{TiO}_{2}$ enhances the photocatalytic activity of titania and also imparts biocidal properties to the modified material, according to the literature [54]. In other work, the PP-AgNPs showed antibacterial activity toward E. coli and $S$. aureus via the release of oxygen reactive species and $\mathrm{Ag}$ ion diffusion mechanism; thus, the inhibition rates enhanced, potentializes the biocidal effect [55], corroborating with our research work. 


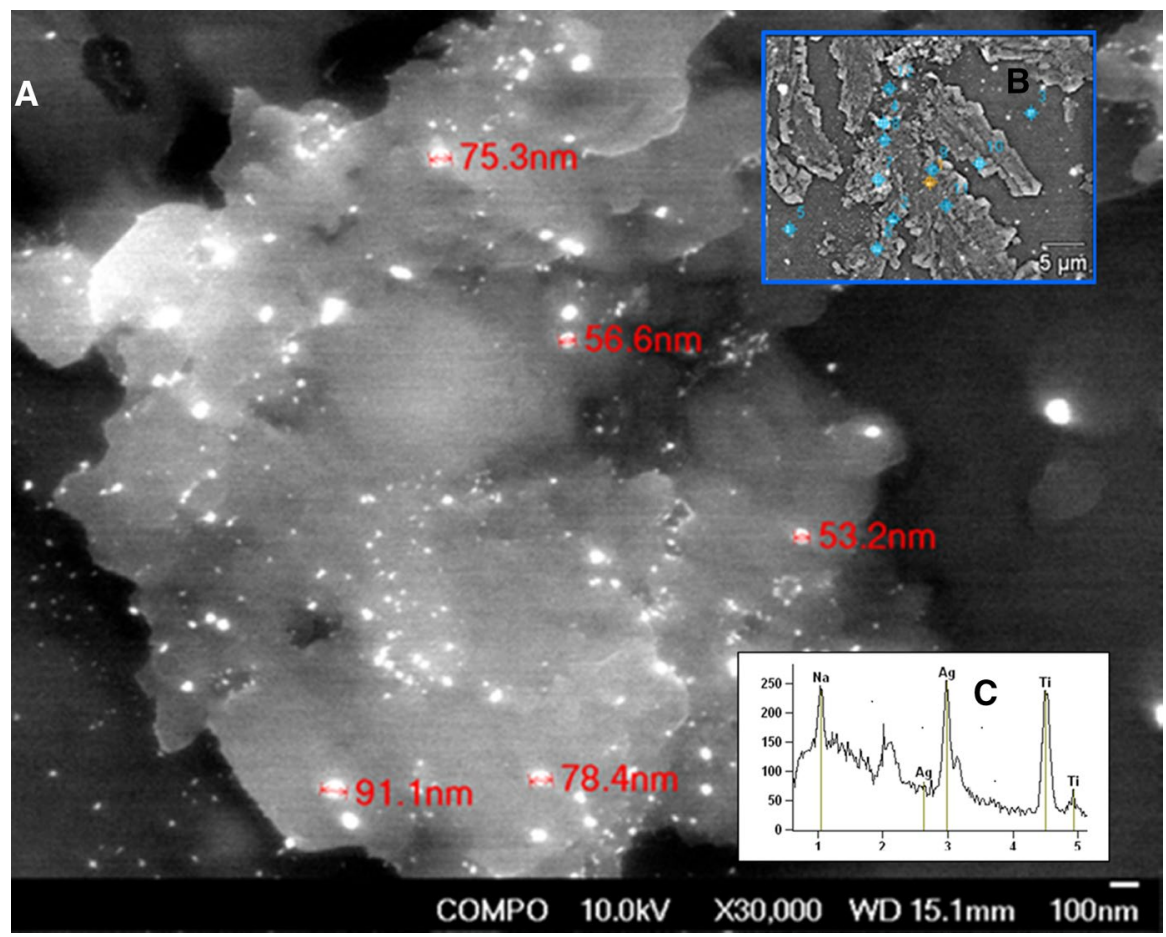

Fig. 4 FESEM micrographs of film surface: A PENC1 (scale = $100 \mathrm{~nm}), \mathbf{B}$ PENC1 (scale $=5 \mu \mathrm{m})$ and $\mathbf{C}$ EDX Spectrum of PENC1

\section{SEM analysis}

Figures 5 and 6 show the SEM micrographs of the nanocomposite film PENC1 and PENC2.

Energy-dispersive X-ray spectroscopy (EDX) was used to analyze the elementary constituents of the PENC thin films. Figure 5 displays the spectrum of PENC films obtained by elemental microprobe analysis of EDX. The results showed that titanium at a concentration of $1.27 \%$ and silver at $0.17 \%$ were the principal elements of PENC films.

EDX analysis also confirmed the presence of elemental silver at a concentration of $0.13 \%$, titanium $0.46 \%$, and silicon $0.16 \%$ as measured on thin film surfaces. The metal elements have a uniform distribution which favors the biocidal interaction by contact with bacteria.

\section{Thermal characterization (DSC and TG)}

The DSC results concerning on the $\mathrm{Tm}_{2}$ and $\mathrm{X}_{C}$ results are presented in Table 3 and refers to the DSC curves, Fig. 7. 

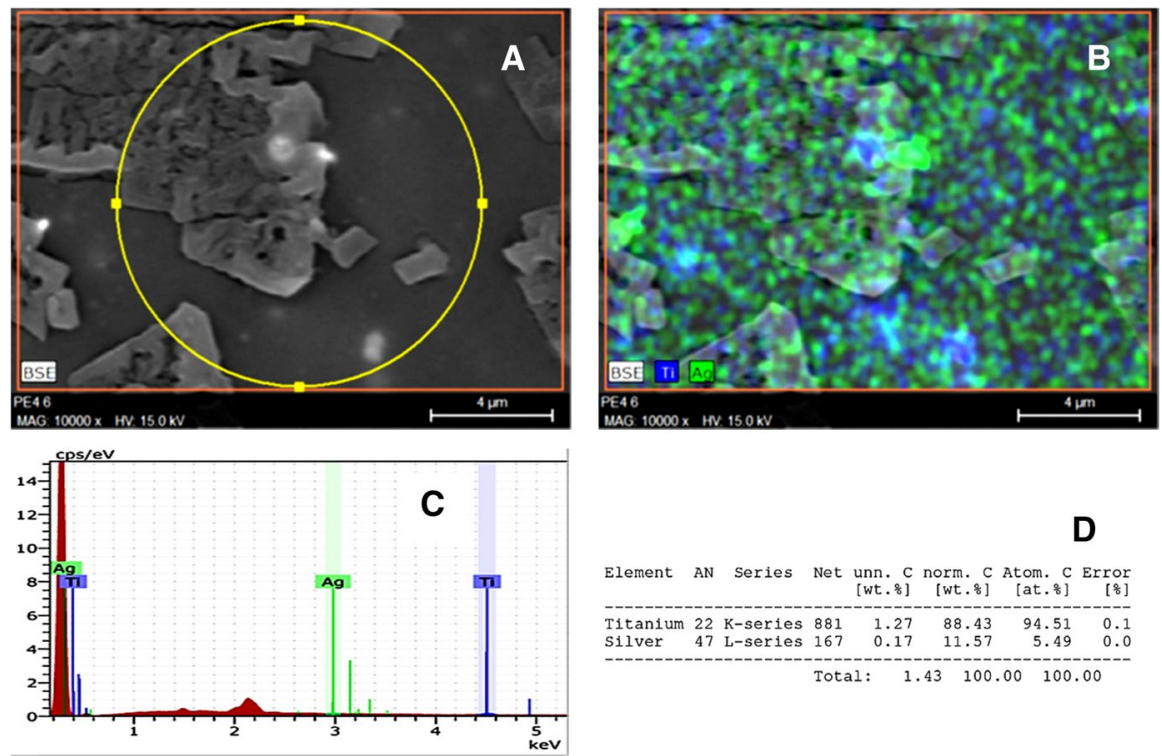

Fig. 5 SEM electron images and SEM-EDX elemental signal maps for PENC1: A PENC1 on the surface, $($ scale $=4 \mu \mathrm{m}), \mathbf{B}$ SEM-EDX showed blue dots referring to titanium and green dots to the clusters of silver nanoparticles; C EDX and D Semi-quantitative analysis of Ti and Ag
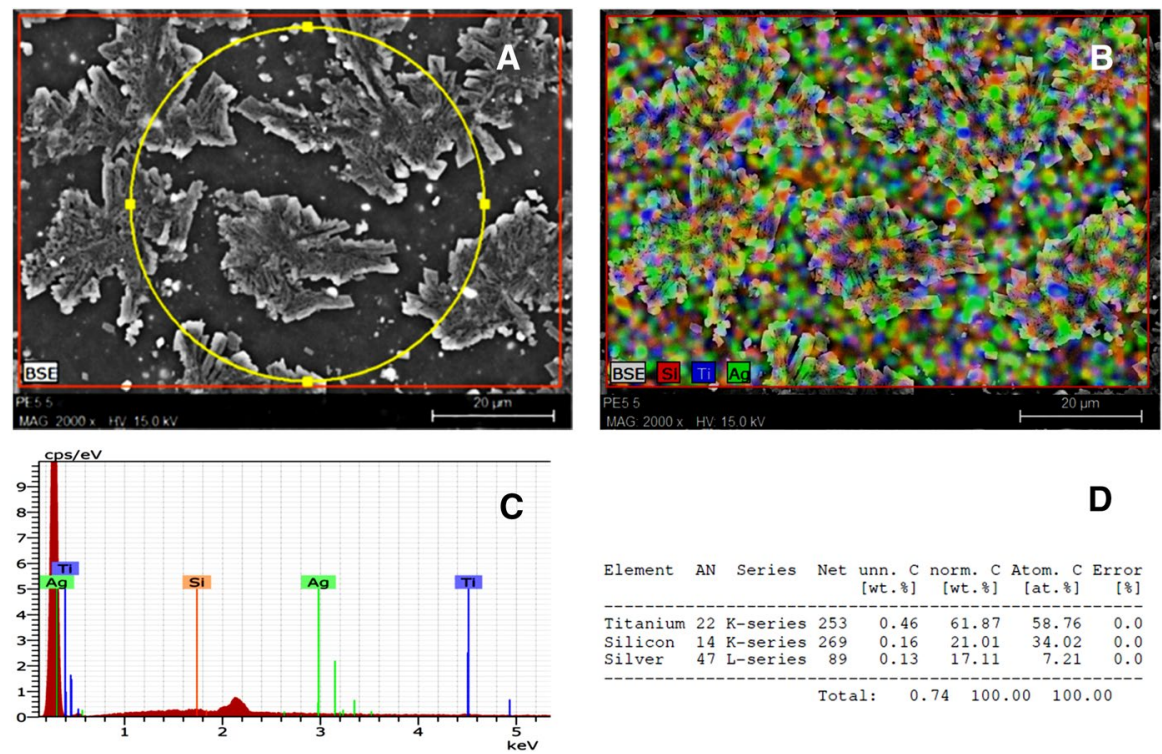

D

\begin{tabular}{|c|c|c|c|c|c|c|c|}
\hline Element & AN & Series & Net & $\begin{array}{l}\text { unn. C } \\
\text { [wt. } 8]\end{array}$ & $\begin{array}{r}\text { norm. C } \\
\text { [wt. \% }]\end{array}$ & $\begin{array}{r}\text { Atom. C } \\
\text { [at. of] }\end{array}$ & $\begin{array}{r}\text { Error } \\
{[? t]}\end{array}$ \\
\hline Titanium & 22 & K-series & 253 & 0.46 & 61.87 & 58.76 & 0.0 \\
\hline Silicon & 14 & $\mathrm{~K}$-series & 269 & 0.16 & 21.01 & 34.02 & 0.0 \\
\hline Silver & 47 & L-series & 89 & 0.13 & 17.11 & 7.21 & 0.0 \\
\hline
\end{tabular}

Fig. 6 SEM electron images and SEM-EDX elemental signal maps for PENC2: A PENC2 on surface, $($ scale $=20 \mu \mathrm{m})$, B SEM-EDX - mapping image of showed orange dots referring silicon, blue dots referring titanium and green dots are clusters of silver nanoparticles; C EDX, and D Semi-quantitative analysis (elemental contents) of $\mathrm{Si}, \mathrm{Ti}$, and $\mathrm{Ag}$ 
Table 3 DSC data of PENC samples during the second run of melting, melt temperature $\left(\mathrm{T}_{m 2}\right)$, and degree of crystallinity $\left(\mathrm{X}_{C}\right)$

\begin{tabular}{lll}
\hline Sample & $\mathrm{T}_{m 2}\left({ }^{\circ} \mathrm{C}\right)$ & 2nd $\mathrm{X}_{C}(\%)$ \\
\hline PE0 Pristine & 111.1 & 35.8 \\
PENC1 & 111.5 & 38.3 \\
PENC2 & 111.4 & 36.2 \\
PENC3 & 110.7 & 48.2 \\
PENC4 & 111.7 & 39.0 \\
PENC5 & 112.0 & 41.1 \\
\hline
\end{tabular}

${ }^{*}$ Reduction of Organisms Percent (R\%)

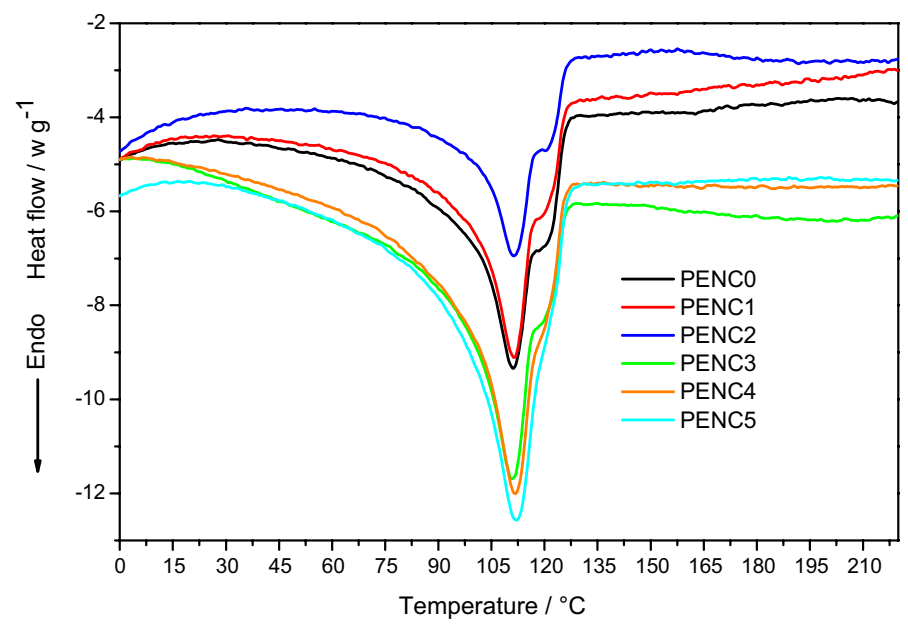

Fig. 7 DSC curves of second heating of the polyethylene nanocomposites films-PENCs

The incorporation of the AgNPs and AgNPs-MMT favored the increase of crystallinity (\%) in all PENC samples. This fact suggests that the AgNPs impart a high efficiency to the heterogeneous nucleation of LDPE in addition to samples with AgNPs-MMT as in the PENC3 sample increased the degree of crystallinity (\%), compared with the control, of 35.8 to $48.2 \%$ (PENC3), indicative of nucleation and possibly release of AgNPs slowly onto the film surface. Benhacine et al. [56] corroborate with that idea and the silver incorporation in MMT plays an important role in the crystallinity degree of PENC that increases when added Ag-MMT. Another important aspect reported by Ghosh et al. [57] is that crystallinity affects the permeability of the nanocomposite films, the permeability decreases with increasing of the crystallinity.

The TG results indicated decomposition $\left(\mathrm{T}_{\text {onset }}\right)$ of the samples, Table 4.

From the information obtained in Table 4, it can be seen that the temperature of degradation $\left(\mathrm{T}_{\text {onset }}\right.$ ) increased with the addition of inorganic particles 
Table 4 Onset temperature (Tonset) for PENC composites after processing

\begin{tabular}{ll}
\hline Sample & $T_{\text {onset }}\left({ }^{\circ} \mathrm{C}\right)$ \\
\hline PE0 Pristine & 431.0 \\
PENC1 & 430.3 \\
PENC2 & 438.0 \\
PENC3 & 438.5 \\
PENC4 & 442.3 \\
PENC5 & 441.0 \\
\hline
\end{tabular}

such as $\mathrm{Ag}, \mathrm{TiO}_{2}$, and MMT, demonstrating a better thermal stability for the nanocomposites.

For PENC4 and PENC5, both irradiated at $25 \mathrm{kGy}$ is verified that radiation contributes to increasing of the thermal stability probable to efficiently reduction of silver avoiding aggregates of nanoparticles $\mathrm{Ag} / \mathrm{TiO}_{2}$, and a slight formation of crosslink which corroborates with higher values of $\mathrm{T}_{\text {onset }}$.

\section{Raman spectroscopy}

Analyzing the Raman spectrum of polyethylene nanocomposite films PENC, Fig. 8, some results were significant and corroborated with the presence of nanoparticles in the films.

The broad band with peaks at 385 and $670 \mathrm{~cm}^{-1}$ are associated with two-phonon states in a $\mathrm{TiO}_{2}$ crystal. The $822 \mathrm{~cm}^{-1}$ lines are associated with the $\mathrm{Eu}(\mathrm{LO})$-vibration $\mathrm{TiO}_{2}$ crystal band [58]. Raman spectra measured the $\mathrm{Si}-\mathrm{Si}$ phonon line position by deconvoluting the spectra into crystalline $520 \mathrm{~cm}^{-1}$ [59].

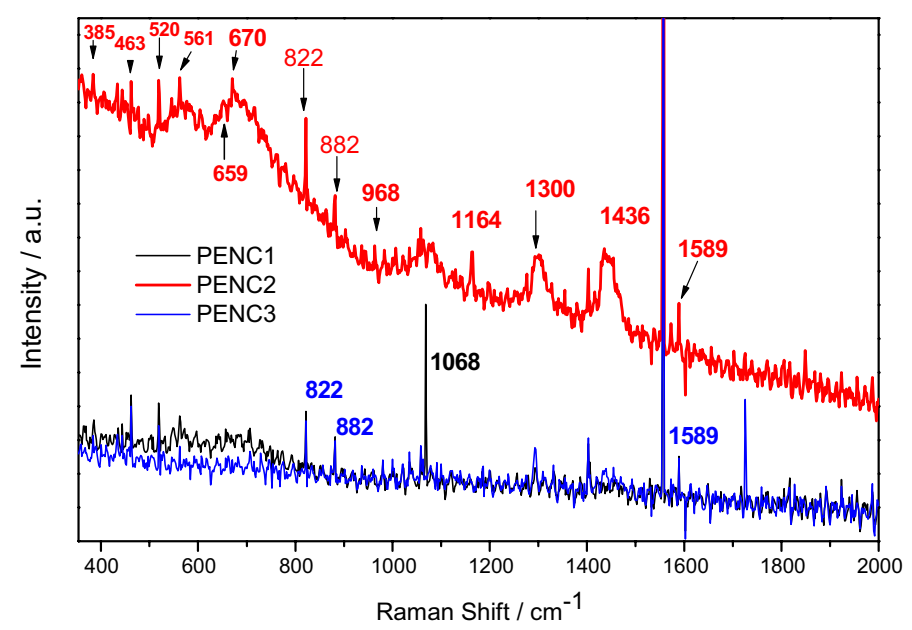

Fig. 8 Raman spectrum of polyethylene nanocomposite films PENC 
Studies conducted by identified $\mathrm{Ag}_{2} \mathrm{O}$ Raman located at $1068 \mathrm{~cm}^{-1}$ [60], $882 \mathrm{~cm}^{-1} \mathrm{Si}-\mathrm{O}$ stretching [61], and $1436 \mathrm{~cm}^{-1}$ band is associated with amino group [62]. The spectra in $1300 \mathrm{~cm}^{-1} \mathrm{CH}_{2}-\mathrm{Si}$ wagging modes [63], 968 and $1164 \mathrm{~cm}^{-1}$ $v(\mathrm{SiOSi})$ [64]. The peak appearing at $659 \mathrm{~cm}^{-1}$ is attributed to the presence of PVP stabilized silver nanoparticles [65]. The broad and intense peak at $1589 \mathrm{~cm}^{-1}$ was attributed to the enhancement of Raman lines by carbon polymeric segments absorbed on silver oxide [66].

\section{Mechanical Properties}

Figure 9 shows the recorded tensile strength and tensile strain (elongation) results of the films.

The PE0 and PENC4 samples showed very close tensile stress at yield values, 20 and $17 \mathrm{MPa}$, but tensile strain at break with little variation 127 and $115 \%$. The other PENC1, 2, 3, and 5 samples showed very significant values of tensile strain at break ranging from 218 to $352 \%$.

\section{Conclusions}

These polyethylene nanocomposites films having silver nanoparticles and titanium dioxide synthesized showed antibacterial efficiency. All samples showed expressive values of microorganisms death by contact, using the Escherichia coli and Staphylococcus aureus, mainly in the irradiated samples PENC4 and PENC5. Polyethylene films (LDPE/LLDPE) using $\mathrm{Ag} / \mathrm{TiO}_{2} / \mathrm{MMT}$ nanocomposites obtained via extrusion have biocidal properties and can be promising materials in medical applications, food packaging to prevent bacterial contamination. We highlighted that the films presented very significant elongation values concerning pure LDPE. It is essential

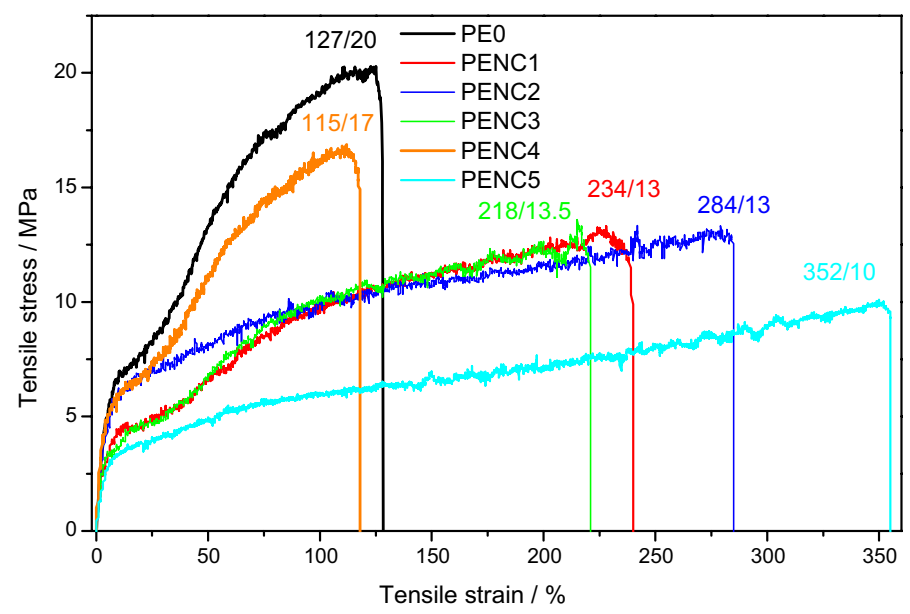

Fig. 9 The stress-strain curves of PENC films 
to consider that the silver nanoparticles and titanium dioxide used to manufacture of polyethylene films did not interfere as contaminants in the ecotoxicity tests with Echinometry lucunter since the larval development was normal.

The nanocomposites were effective against tested pathogenic microorganisms due to the efficiency of irradiation in the reduction of ions to nanosilver in the $\mathrm{TiO}_{2} /$ MMT surface with the consequence of total bacteria death, reaching values close to zero.

Reduction in aggregates size due to the gamma irradiation of the surface films performed a more stable bactericide activity. The obtained materials can be used in various applications with antimicrobial functions.

Acknowledgements The authors acknowledge financial support for this work from CNEN-IPEN, CLAIPEN, and CCTM-IPEN, for microscopy analysis (FESEM and SEM-EDX), Multipurpose Gamma Irradiation Facility at the Radiation Technology Center-CTR-IPEN and ControlBio by biocide testing.

\section{References}

1. Zare Y, Shabani I (2016) Polymer/metal nanocomposites for biomedical applications. Mater Sci Eng C 60:195-203

2. Palza H (2015) Antimicrobial polymers with metal nanoparticles. Int J Mol Sci 16:2099-3016

3. Le-Ouay B, Stellacci F (2015) Antibacterial activity of silver nanoparticles: a surface science insight. Nano Today 10:339-354

4. Tomacheski D, Pittol M, Lopes APM, Simões DN, Ribeiro VF, Santana RMC (2018) Effects of weathering on mechanical, antimicrobial properties and biodegradation process of silver loaded TPE compounds. J Polym Environ 26:73-82

5. James B, Ramakrishnan R, Aprem AS (2021) Development of environmentally safe biodegradable, antibacterial surgical sutures using nanosilver particles. J Polym Environ 29:2282-2288

6. Kalaycı OA, Comert FB, Hazer B, Atalay T, Cavicchi KA, Cakmak M (2010) Synthesis, characterization, and antibacterial activity of metal nanoparticles embedded into amphiphilic comb-type graft copolymer. Polym Bull 65:215-226

7. Zhang S, Wang L, Liang X, Vorstius J, Keatch R, Corner G, Nabi G, Davidson F, Gadd GM, Zhao Q (2019) Enhanced antibacterial and antiadhesive activities of silver-PTFE nanocomposite coating for urinary catheters. ACS Biomater Sci Eng 5:2804-2814

8. Gallo J, Panacek A, Prucek R, Kriegova E, Hradilova S, Hobza M, Holinka M (2016) Silver nanocoating technology in the prevention of prosthetic joint infection. Materials 9(337):1-30

9. Pavoski G, Kalikoski R, Souza G, Brum LFW, Santos C, Marked AA, Santos JHZ, Font X, Erba I, Galland GB (2018) Synthesis of polyethylene/silica-silver nanocomposites with antibacterial properties by in situ polymerisation. Eur Polym J 106:92-101

10. Deshmukha SP, Patila SM, Mullania SB, Delekara SD (2019) Silver nanoparticles as an effective disinfectant: a review. Mater Sci Eng C 97:954-965

11. Hazer B, Kalaycı OA (2017) High fluorescence emission silver nano particles coated with poly(styrene-g-soybean-oil) graft copolymers: Antibacterial activity and polymerization kinetics. Mater Sci Eng C 74:259-269

12. Wei X, Yang Z, Tay SL, Gao W (2014) Photocatalytic $\mathrm{TiO}_{2}$ nanoparticles enhanced polymer antimicrobial coating. Appl Surf Sci 290:274-279

13. Colunga JGM, Valdes SS, Valle LFR, Vargas ER, Orta CA, Gonzalez JAR, González CJE, Cantú RB, Ramírez TL (2020) Effect of ultrasonic irradiation on low-density polyethylene molecular structure. Polym Bull 77:5303-5321

14. Liang JZ, Tan LC, Wang KJ, Li FJ, Zhang SD (2015) Melt elongation flow behaviour of LDPE/ LLDPE blends. Polym Test 41:133-139 
15. Passador FR, Ruvolo-Filho AC, Pessan LA (2016) Structural, thermal, and gas transport properties of HDPE/LLDPE blend-based nanocomposites using a mixture of HDPE-g-MA and LLDPE-g-MA as compatibilizer. Polym Eng Sci 56(7):765-775

16. Wang D, Yang B, Chen QT, Chen J, Su LF, Chen P, Zheng ZZ, Miao JB, Qian JS, Xia R, Shi Y (2019) A facile evaluation on melt crystallization kinetics and thermal properties of low-density polyethylene (LDPE)/recycled polyethylene terephthalate (RPET) blends. Adv Ind Eng Polym Res 2:126-135

17. Paxton NC, Allenby MC, Lewis PM, Woodruff MA (2019) Biomedical applications of polyethylene. Eur Polym J 118:412-428

18. Coutinho FMB, Mello IL, Maria LCS (2003) Polietileno: principais tipos, propriedades e aplicações. Polímeros: Ciência e Tecnologia 13:1-13

19. Yalcinkaya F, Lubasova D (2017) Quantitative evaluation of antibacterial activities of nanoparticles $\left(\mathrm{ZnO}, \mathrm{TiO}_{2}, \mathrm{ZnO} / \mathrm{TiO}_{2}, \mathrm{SnO}_{2}, \mathrm{CuO}, \mathrm{ZrO}_{2}\right.$, and $\left.\mathrm{AgNO}_{3}\right)$ incorporated into polyvinyl butyral nanofibers. Polym Adv Technol 28:137-140

20. Rehana M, Nadab AA, Khattabd TA, Abdelwahed NAM, El-Kheir AAA (2020) Development of multifunctional polyacrylonitrile/silver nanocomposite films: antimicrobial activity, catalytic activity, electrical conductivity, UV protection and SERS-active sensor. J Mater Res Technol 9(4):9380-9394

21. Hazer DB, Mut M, Dinçer N, Saribas Z, Hazer B, Özgen T (2012) The efficacy of silver-embedded polypropylene-grafted polyethylene glycol-coated ventricular catheters on prevention of shunt catheter infection in rats. Childs Nerv Syst 28:839-846

22. Gök ZG, Demiral A, Bozkaya O, Yiğitoğlu M (2021) In situ synthesis of silver nanoparticles on modified poly(ethylene terephthalate) fibers by grafting for obtaining versatile antimicrobial materials. Polym Bull 78:7241-7260

23. Gök ZG, Günay K, Arslan M, Yiğitoğlu M, Vargel I (2020) Coating of modified poly(ethylene terephthalate) fibers with sericin-capped silver nanoparticles for antimicrobial application. Polym Bull 77:1649-1665

24. Parra DF, Marchini LG, Komatsu LGH, Oliveira CB, Oliani WL, Rangari VK (2021) AgNPs@ $\mathrm{ZnO}$ hybride nanoparticles infused thermoplastic polyester elastomer and their biocide effect. SN Appl Sci 3:392-405

25. Thiel J, Pakstis L, Buzby S, Raffi M, Ni C, Pochan DJ, Shah SI (2007) Antibacterial properties of silver doped titania. Small 3(5):799-803

26. Oliani WL, Lima LFCP, Rogero SO, Riella HG, Lugao AB, Parra DF (2015) AgNPs polypropylene gel films thermal study and antibacterial activity. J Therm Anal Calorim 119:1963-1970

27. Nguyen VT, Tabish M, Yasin G, Bilal M, Nguyen TH, Van CP, Nguyen-Tri P, Gupta RK, Nguyen TA (2021) A facile strategy for the construction of TiO2/Ag nanohybrid-based polyethylene nanocomposite for antimicrobial applications. Nano-Struct. Nano-Obj 25:100671

28. Nithyadevi D, Kumar PS, Mangalaraj D, Ponpandian N, Viswanathan C, Meena P (2015) Improved microbial growth inhibition activity of bio-surfactant induced $\mathrm{Ag}-\mathrm{TiO}_{2}$ core shell nanoparticles. Appl Surf Sci 327:504-516

29. Moongraksathum B, Chien MY, Chen YW (2019) Antiviral and antibacterial effects of silver doped $\mathrm{TiO}_{2}$ prepared by the peroxo sol gel method. J Nanosci Nanotechnol 19(11):7356-7362

30. Girase B, Depan D, Shah JS, Xu W, Misra RDK (2011) Silver-clay nanohybrid structure for effective and diffusion controlled antimicrobial activity. Mater Sci Eng C 31:1759-1766

31. Giraldo LF, Camilo P, Kyu T (2016) Incorporation of silver in montmorillonite-type phyllosilicates as potential antibacterial material. Current Opinion Chem Eng 11:7-13

32. Savas LA, Hancer M (2015) Montmorillonite reinforced polymer nanocomposite antibacterial film. Appl Clay Sci 108:40-44

33. Umasankareswari T, Singh G, Prabha SS, Al-Hashem A, Kumaran SS, Rajendran S (2020) Nanotoxicity: Prevention and antibacterial applications of nanomaterials. Toxicity of silver and other metallic nanoparticles. Elsevier, pp 125-141

34. Oliani WL, Parra DF, Komatsu LGH, Lincopan N, Rangari VK, Lugao AB (2017) Fabrication of polypropylene/silver nanocomposites for biocidal applications. Mater Sci Eng C 75:845-853

35. Fabrega J, Luoma SN, Tyler CR, Galloway TS, Lead JR (2011) Silver nanoparticles: Behaviour and effects in the aquatic environment. Environ Inter 37:517-531

36. Ribeiro MB, Furley T, Spago FR, Paredes E (2018) First steps towards Echinometra lucunter embryo cryopreservation. Cryobiology 80:51-54 
37. Souza LS, Pusceddu FH, Cortez FS, Orte MR, Seabra AA, Ribeiro ACDA, Casillas TADV, Pereira CDS (2019) Harmful effects of cocaine by product in the reproduction of sea urchin in different ocean acidification scenarios. Chemosphere 236:124284

38. Maan AMC, Hofman AH, Vos WM, Kamperman M (2020) Recent developments and practical feasibility of polymer-based antifouling coatings. Adv Funct Mater 30(32):2000936

39. Colunga JGM, Valdes SS, Cardenas AB, Vargas ER, Valle LFR, Cantu RB, Martinez ABE, Lopez SS, Ramirez TL, Lafleur PG, Karami S (2018) Dispersion and exfoliation of nanoclays in itaconic acid funcionalized LDPE by ultrasound treatment. J Appl Polym Sci 135(20):46260

40. Stucchi M, Bianchi CL, Argirusis C, Pifferi V, Neppolian B, Cerrato G, Boffito DC (2018) Ultrasound assisted synthesis of Ag-decorated $\mathrm{TiO}_{2}$ active in visible light. Ultrason Sonochem 40:282-288

41. USEPA - United States Environmental Protection Agency (1995) Short-term methods for estimating the chronic toxicity of effluents and receiving waters to west coast marine and estuarine organisms, first ed. [EPA/600/R-95e136]

42. JIS Z 2801 (2010) Antibacterial products - Test for antibacterial activity and efficacy

43. Brandrup J, Immergut EH, Grulke EA (1999) Polymer Handbook. Wiley-Interscience 1, 445-450

44. Hoffmann JD, Miller RL (1997) Kinetics of crystallization from the melt and chain folding in polyethylene fractions revisited: theory and experiment. Polymer 38(13):3151-3212

45. ASTM D882 (2018) Standard test method for tensile properties of thin plastic sheeting.

46. Kilinc YB, Koc RC, Zorlu T, Ozdemir B, Karavelioglu Z, Egil AC, Gunduz SK (2018) Silver nanoparticles - Fabrication. Characterization and applications, assessment of nanotoxicity and safety profiles of silver nanoparticles. IntechOpen, pp 185-208

47. Maurer LL, Meyera JN (2016) A systematic review of evidence for silver nanoparticle-induced mitochondrial toxicity. Environ Sci Nano 3:311-322

48. Grassi G, Landi C, Torre CD, Bergami E, Binib L, Corsi I (2019) Proteomic profile of the hard corona of charged polystyrene nanoparticles exposed to sea urchin Paracentrotus lividus coelomic fluid highlights potential drivers of toxicity. Environ Sci Nano 6:2937-2947

49. Wu TS, Wang KX, Li GD, Sun SY, Sun J, Chen JS (2010) Montmorillonite supported Ag/TiO 2 nanoparticles: an efficient visible-light bacteria photodegradation material. ACS Appl Mater Interfaces 2(2):544-550

50. Damm C, Munstedt H, Rosch A (2008) The antimicrobial efficacy of polyamide 6/silver nano and microcomposites. Mater Chem Phys 108:61-66

51. That TMT, Jungnickel BJ (1999) Water diffusion into transcrystalline layers on polypropylene. J Appl Polym Sci 74:3275-3285

52. Nguyen TKL, Nguyen TAT, Dang VP, Nguyen ND, Le AQ, Nguyen QH (2013) Synthesis of silver nanoparticles deposited on silica by gamma-irradiation and preparation of $\mathrm{PE} / \mathrm{Ag}$ nano compound masterbatches. Adv Nat Sci Nanosci Nanotechnol 4:45004-45008

53. Zheng J, Clogston JD, Patri AK, McNeil SE, Dobrovolskaia MA (2016) Handbook of immunological properties of engineered nanomaterials. In: Sterilization case study 2: Effects of sterilization techniques on silver nanoparticles 1, pp. 93-108

54. Imhof A (2001) Preparation and characterization of titania-coated polystyrene spheres and hollow titania shells. Langmuir 17:3579-3585

55. Cao G, Lin H, Kannan P, Wang C, Zhong Y, Huang Y, Guo Z (2018) Enhanced antibacterial and food simulant activities of silver nanoparticles/polypropylene nanocomposite films. Langmuir 34(48):14537-14545

56. Benhacine F, Hadj-Hamou AS, Habi A (2016) Development of long-term antimicrobial poly ( $\varepsilon$-caprolactone)/silver exchanged montmorillonite nanocomposite films with silver ion release property for active packaging use. Polym Bull 73:1207-1227

57. Ghosh SK, Das TK, Ghosh S, Ganguly S, Nath K, Das NC (2020) Physico-mechanical, rheological and gas barrier properties of organoclay and inorganic phyllosilicate reinforced thermoplastic films. J Appl Polym Sci 138(4):49735

58. Denisov VN, Mavrin BN, Podobedov VB, Sterin KE (1980) Two-phonon hyper-Raman scattering and polariton spectra in rutile crystal. Optics Comm 34(3):357-360

59. Saleh R, Nickel NH (2003) Raman spectroscopy of $\beta$-doped microcrystalline silicon films. Thin Solid Films 427:266-269

60. Advances in medical and surgical engineering (2020) Edited by Wagar Ahmed et al., Academic Press - Elsevier, p. 220 
61. Jehlicka J, Vítek P, Edwards HGM, Heagraves M, Capoun T (2009) Application of portable Raman instruments for fast and non-destructive detection of minerals on outcrops. Spectrochim Acta A 73:410-419

62. Molecular spectroscopy: A Quantum chemistry approach (2019) Edited by Yukihiro Ozaki et al. In: Density functional theoretical study on surface-enhanced Raman spectroscopy of $\mathrm{CH}_{2} / \mathrm{NH}_{2}$ Wagging Modes in $\mathrm{p}-\pi$ conjugated molecules on noble metal surfaces, Wiley-VCH, 555

63. Nanotechnology in catalysis (2004) Editors: Bing Zhou, Scott Han, Robert Raja, Gabor A. Somorjai, Spring, 1, 298

64. Spectroscopic properties of inorganic and organometallic compounds (1975) N. N. Greenwood. In: The chemical society burlington house, 8, 265

65. Perkas N, Shuster M, Amirian G, Koltypin Y, Gedanken A (2008) Sonochemical immobilization of silver nanoparticles on porous polypropylene. J Polym Sci A Polym Chem 46:1719-1729

66. Alfaro JAA, Valdes SS, Valle LFR, Ortiz HO, Nonell JM, Soto APP, Cespedes RIN, Mercado YAP, Belmontes FA (2013) Ultrasound irradiation coating of silver nanoparticles on ABS sheet surface. J Inorg Organomet Polym 23:673-683

Publisher's Note Springer Nature remains neutral with regard to jurisdictional claims in published maps and institutional affiliations. 